\title{
A concept of an automated function control for ambient aerosol measurements using mobility particle size spectrometers
}

\author{
A. Schladitz ${ }^{1,2}$, M. Merkel $^{2}$, S. Bastian ${ }^{1}$, W. Birmili ${ }^{2}$, K. Weinhold ${ }^{2}$, G. Löschau ${ }^{1}$, and A. Wiedensohler ${ }^{2}$ \\ ${ }^{1}$ Saxon State Office for Environment, Agriculture and Geology (LfULG), Pillnitzer Platz 3, 01326 Dresden, Germany \\ ${ }^{2}$ Leibniz Institute for Tropospheric Research (TROPOS), Permoserstraße 15, 04318 Leipzig, Germany
}

Correspondence to: A. Schladitz (alexander.schladitz@smul.sachsen.de)

Received: 30 August 2013 - Published in Atmos. Meas. Tech. Discuss.: 9 December 2013

Revised: 17 March 2014 - Accepted: 17 March 2014 - Published: 28 April 2014

\begin{abstract}
An automated function control unit was developed to regularly check the ambient particle number concentration derived from a mobility particle size spectrometer as well as its zero-point behaviour. The function control allows unattended quality assurance experiments at remote air quality monitoring or research stations under field conditions. The automated function control also has the advantage of being able to get a faster system stability response than the recommended on-site comparisons with reference instruments. The method is based on a comparison of the total particle number concentration measured by a mobility particle size spectrometer and a condensation particle counter while removing diffusive particles smaller than $20 \mathrm{~nm}$ in diameter. In practice, the small particles are removed by a set of diffusion screens, as traditionally used in a diffusion battery. Another feature of the automated function control is to check the zero-point behaviour of the ambient aerosol passing through a high-efficiency particulate air (HEPA) filter.

The performance of the function control is illustrated with the aid of a 1-year data set recorded at Annaberg-Buchholz, a station in the Saxon air quality monitoring network. During the period of concern, the total particle number concentration derived from the mobility particle size spectrometer slightly overestimated the particle number concentration recorded by the condensation particle counter by $2 \%$ (grand average). Based on our first year of experience with the function control, we developed tolerance criteria that allow a performance evaluation of a tested mobility particle size spectrometer with respect to the total particle number concentration. We conclude that the automated function control enhances the quality and reliability of unattended long-term particle number size distribution measurements. This will have beneficial ef-
\end{abstract}

fects for intercomparison studies involving different measurement sites, and help provide a higher data accuracy for cohort health and climate research studies.

\section{Introduction}

For more than three decades, high-resolution particle number size distributions (PNSD) have been measured worldwide in atmospheric science to investigate the evolution of aerosol particles in time and space (Bates et al., 1998; Heintzenberg, 2009; Huebert et al., 2003; Raes et al., 2000). The PNSD serves as a basic parameter, for example, to calculate atmospheric particle light scattering effects and also to estimate the number of cloud condensation nuclei (Romakkaniemi et al., 2012). Moreover, the number concentration of particles originating from secondary formation has been recognized as playing a certain role in a feedback mechanism moderating climate change (Paasonen et al., 2013). The PNSD also serves as the most basic parameter to describe aerosol particles in atmospheric chemistry transport models. Consequently, PNSD measurements have been implemented in many atmospheric observation networks including WMO-GAW (The World Meteorological Organisation's Global Atmosphere Watch Programme), EUSAAR (European Supersites for Atmospheric Aerosol Research), ACTRIS (Aerosols, Clouds, and Trace Gases Research Infrastructure Network) (Asmi et al., 2011), and in the German Ultrafine Aerosol Network (Birmili et al., 2009).

Additional motivation for atmospheric PNSD measurements derives from the need to better characterize the healthrelated particle exposure (Russell and Brunekreef, 2009; 
Wichmann et al., 2000). Although not part of the legal framework involving PMx metrics (particulate matter $<10 \mu \mathrm{m}$ and $<2.5 \mu \mathrm{m}$ ), PNSD measurements are currently used in air quality monitoring networks to interpret the success of clean air plans in congested urban areas (Löschau et al., 2012, 2013).

The Saxon State Office for Environment, Agriculture and Geology (LfULG), Dresden, Germany has been a driving force to integrate PNSD measurements into their air quality monitoring network in Saxony. Saxony is situated in the south-eastern part of Germany, sharing borders with Poland and the Czech Republic. At present, three stations of the Saxon air quality monitoring network are equipped with mobility particle size spectrometers designed by the Leibniz Institute for Tropospheric Research (TROPOS), Leipzig, Germany: the roadside station Dresden-Nord (EU-code DESN061), the urban background station Dresden-Winckelmannstraße (EU-code DESN092), and the urban background station Annaberg-Buchholz (EUcode DESN001). Detailed information about the stations can be found by using the EU-codes on the web page of the Federal Environment Agency of Germany (UBA, 2013).

For a long time, atmospheric PNSD measurements have suffered from the lack of direct connection to a standard, i.e. to a reference method. Unlike for trace gases, there is no particle number concentration available that could be freely conveyed between a reference laboratory and a measurement station. As a pragmatic solution, PNSD measurements have typically been quality assured by short-term instrumental intercomparisons in a central laboratory (Wiedensohler et al., 2012). It is, however, desirable to verify the performance of PNSD measurements under real field conditions and quasicontinuously.

For a systematic quality control of a PNSD measurement, two parameters should be checked: particle number concentration (PNC) and particle size. The correct sizing of a mobility particle size spectrometer can be checked by using certified size standards (e.g. NIST ${ }^{1}$ certified polystyrene size standards). A particle number concentration standard is nonexistent at the current state of the art. Thus, the direct verification of the correct count rate of a mobility particle size spectrometer is not possible. In this work, we present an operational quality control using a reference method.

The LfULG in cooperation with TROPOS developed an automated function control and tested it for suitability in an air quality monitoring network. The method is based on performing a comparison between the mobility particle size spectrometer and a condensation particle counter (CPC) as a reference method for the total PNC. It can be operated quasi-continuously, in comparison to the rather sporadic onsite comparisons against a reference mobility particle size spectrometer three or four times a year. Motivation behind

\footnotetext{
${ }^{1}$ National Institute of Standards and Technology, Gaithersburg, MD, USA
}

the automated function control was to reduce the efforts related to on-site comparisons with reference mobility particle size spectrometer and thus to reduce the operating expenses. Furthermore, the automated function control is expected to uncover instrumental problems more quickly, thus enabling faster intervention by the operator, reducing instrumental down times, and enhancing overall data reliability.

\section{Instrumental}

Figure 1 illustrates a scheme of a mobility particle size spectrometer that is equipped with the automated function control. The basic closed-loop mobility particle size spectrometer shown on the right of the sketch fulfils the ACTRIS recommendations (Wiedensohler et al., 2012). All parts of the automated function control are confined by a red dashed line. The purpose of the uppermost motor-driven ball valves is to switch the aerosol flow between (a) ambient aerosol, (b) ambient aerosol passing through a HEPA filter (referred to as zero air), and (c) ambient aerosol passing through a set of 40 diffusion screens. Technical data and design of the diffusion screens are given further down in this paragraph. Downstream of the bypass, the aerosol flow of $21 \mathrm{~min}^{-1}$ is split equally into flows of $11 \mathrm{~min}^{-1}$ for the mobility particle size spectrometer and for the transfer CPC.

The transfer CPC is a commercial condensation particle counter (CPC model 3772, TSI Inc., Shoreview, MN, USA) that serves as a transfer standard, and is regularly cycled between the three measurement stations and the calibration facility (WCCAP - World Calibration Center for Aerosol Physics hosted at the Leibniz Institute for Tropospheric Research). The usual procedure is to operate the transfer CPC at a station for about two weeks, and then proceed to the next measurement site. Two weeks correspond with the standard maintenance cycle in the air quality monitoring network performed by the station personnel.

After each cycle, the total PNCs of the transfer CPC and a stationary master CPC are compared at the WCCAP. Beyond that, the transfer CPC and the CPCs from the mobility particle size spectrometers are calibrated against the reference aerosol electrometer (model 3068B, TSI Inc., Shoreview, MN, USA) at the WCCAP twice a year. Our experiences showed that it is recommended to perform service checks of CPCs on a regularly basis. The aerosol electrometer is calibrated at the German metrology institute (PTB) against a well-defined femtoampere source. The calibration of the transfer CPC comprises the determination of the detection efficiency curve of the CPC from 5 up to $40 \mathrm{~nm}$ in particle diameter $\left(D_{\mathrm{p}}\right)$. Details about the calibration procedure can be taken from the ACTRIS recommendations (Wiedensohler et al., 2012). Figure 2 shows the result of the calibration of the transfer CPC on 24 October 2012. For $D_{\mathrm{p}}<20 \mathrm{~nm}$, the detection efficiency curve of the CPC drops steeply, while the current $50 \%$ detection efficiency diameter 


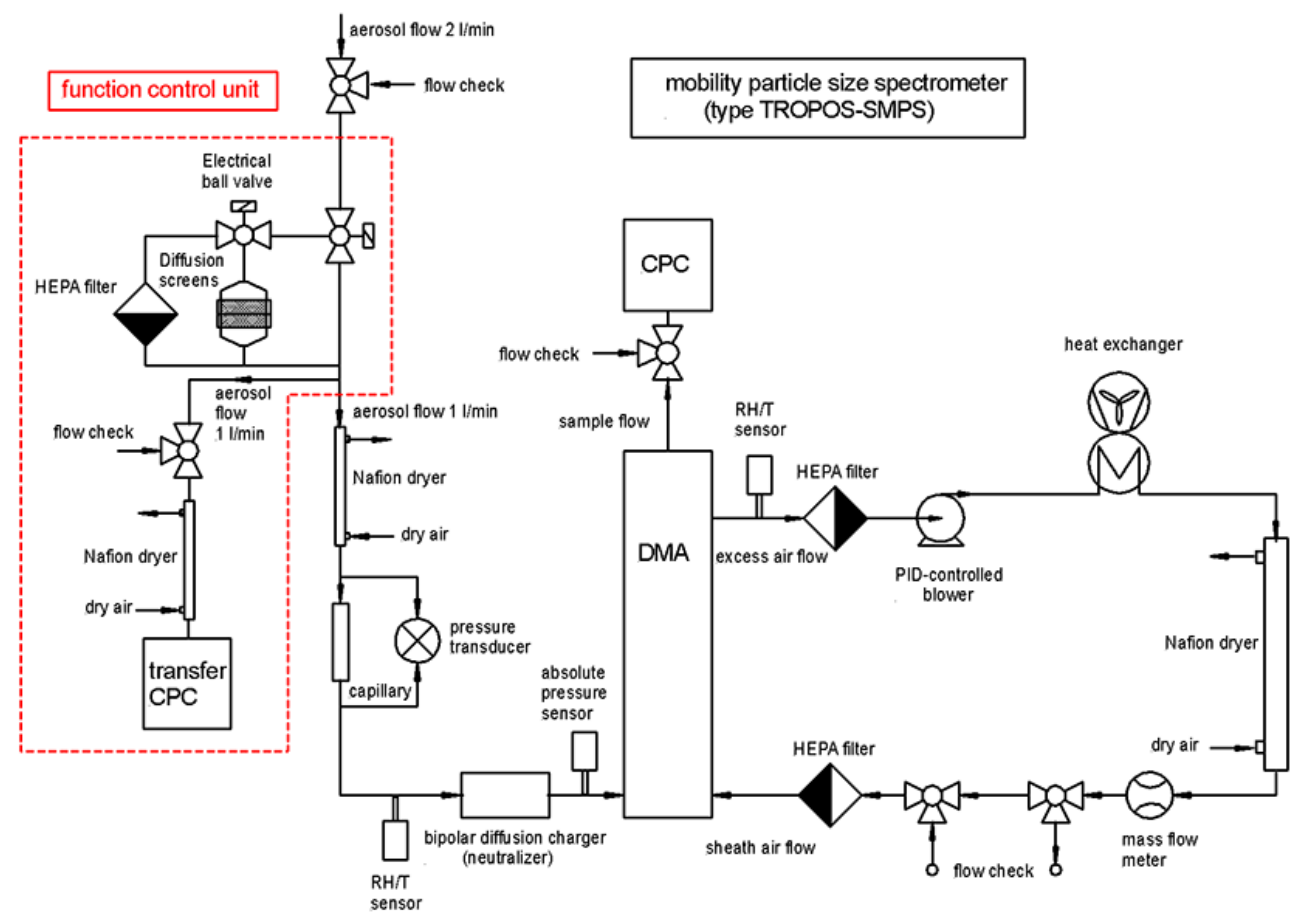

Fig. 1. Scheme of a closed-loop mobility particle size spectrometer equipped with an additional function control unit.

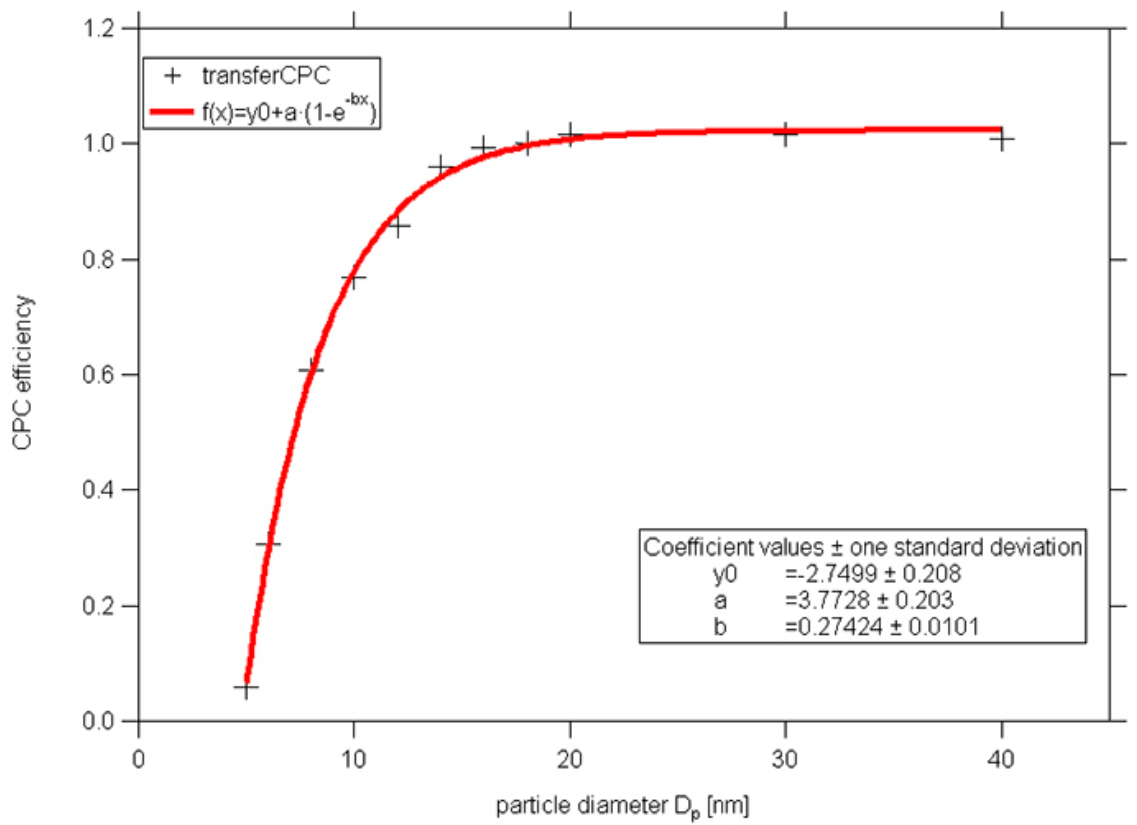

Fig. 2. Detection efficiency curve of the transfer CPC recorded on 24 October 2012.

$D_{\mathrm{p} 50}$ is $7.2 \mathrm{~nm}$ (for comparison, the CPC user manual indicates $\left.D_{\mathrm{p} 50}=10 \mathrm{~nm}\right)$. For $D_{\mathrm{p}}>30 \mathrm{~nm}$, the asymptotic value of the detection efficiency of the transfer CPC approaches $100 \%$. These results were endorsed in a further calibration on 8 August 2013 (not shown here).
The upper graph of Fig. 3 illustrates a comparison of integrated PNC from mobility particle size spectrometer (abbr. $\mathrm{PNC}_{\text {mob. }}$ ) and PNC from the transfer CPC (abbr. $\left.\mathrm{PNC}_{\mathrm{tCPC}}\right)$. These data were aggregated from the urban background station Annaberg-Buchholz for a 1-year period 1 August 2012 to 1 August 2013. For PNC $>5000 \mathrm{~cm}^{-3}$, the scatter plot 

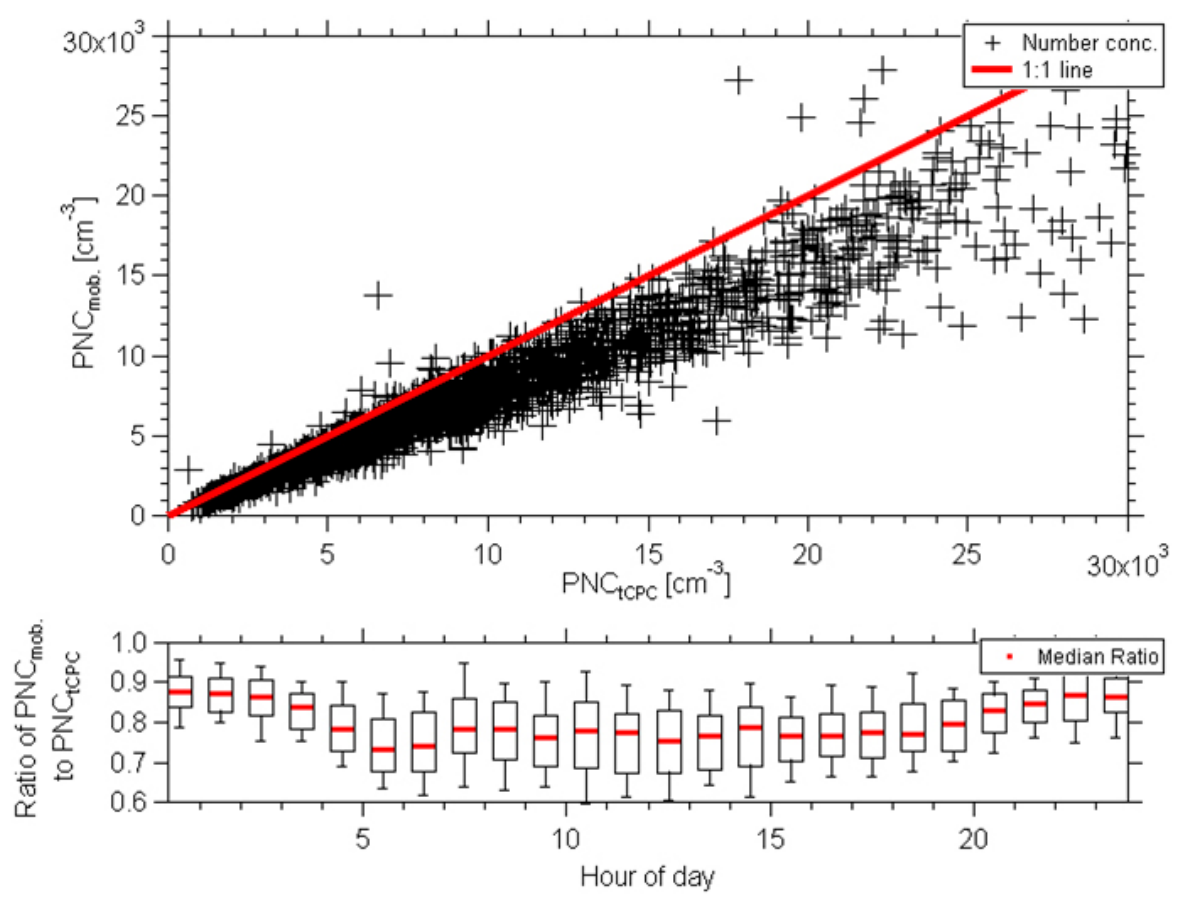

Fig. 3. Comparison of total PNCs, as measured by the mobility particle size spectrometer without diffusion screens $\left(\mathrm{PNC}_{\mathrm{mob}}\right)$ and the transfer CPC $\left(\mathrm{PNC}_{\mathrm{tCPC}}\right)$ for the Annaberg-Buchholz site from 1 August 2012 to 1 August 2013. Upper graph: scatter plot of PNC $\mathrm{mob}_{\text {. }}$ against $\mathrm{PNC}_{\mathrm{tCPC}}$ (black crosses). Lower graph: diurnal variation of the ratio $\mathrm{PNC}_{\mathrm{mob}} / \mathrm{PNC}_{\mathrm{tCPC}}$.

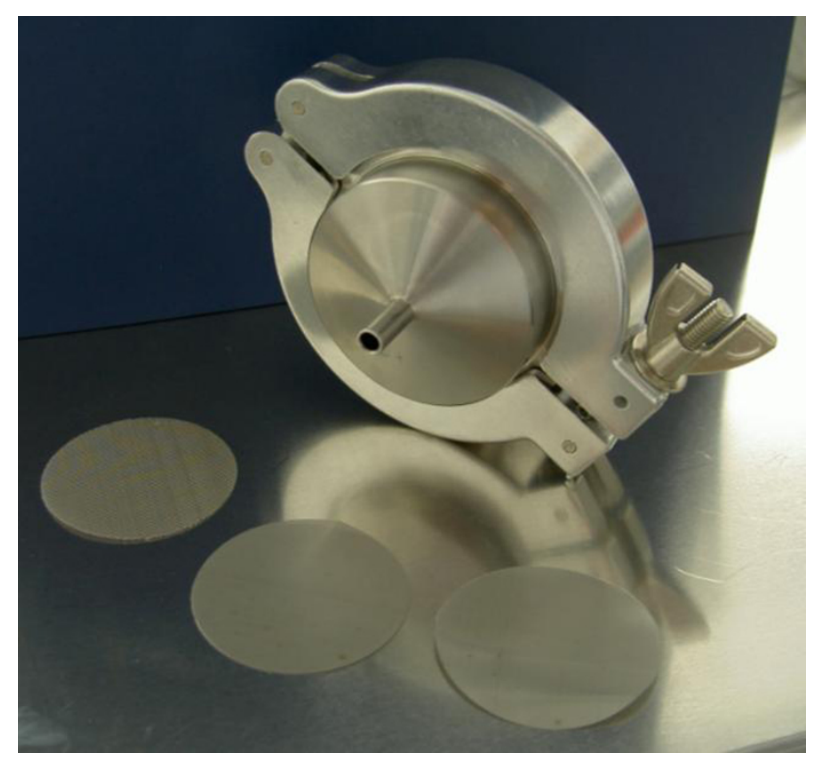

Fig. 4. Picture of the diffusion screens (foreground) and a stainless steel screen holder (background).

deviates from the $1: 1$ line, in particular $\mathrm{PNC}_{\mathrm{mob}}$. underestimates $\mathrm{PNC}_{\mathrm{tCPC}}$. During daytime, the underestimation is highest (cf. lower graph in Fig. 3) when nucleation mode particles are present originating mainly from traffic and photochemical processes. By contrast, the ratio is about 0.9 and the variability is lower during the night. Thus, $\mathrm{PNC}_{\text {mob. }}$ and $\mathrm{PNC}_{\mathrm{tCPC}}$ would be much better comparable if nucleation mode particles are removed.

Mobility particle-size spectrometers have, however, larger uncertainties than CPCs for $D_{\mathrm{p}}<20 \mathrm{~nm}$ due to deviations in precise high voltage power supply especially for very low DMA voltages. Moreover, DMA characteristics, e.g. material used for the insulator, lead to additional losses, which are not considered in the data processing described in Sect. 3. Thus, to ensure comparability between total PNCs derived from mobility particle size spectrometers and CPCs, the automated function control should be equipped with diffusion screens. The purpose of the diffusion screens is, thereby, the removal of the high fluctuating sub- $20 \mathrm{~nm}$ particles and the reduction of the total particle number concentration below $1 \times 10^{4} \mathrm{~cm}^{-3}$.

Figure 4 illustrates the diffusion screens (as traditionally used in a diffusion battery) with a diameter of $47 \mathrm{~mm}$ and the prototype of the screen holder. The custom-made screen holder is made of two stainless steel pieces. Both pieces adhere together via a sleeve and can be opened by a thumbscrew to take out the screens. The commercial diffusion screens (Drahtweberei Pausa GmbH, Pausa/Vogtland, Germany) are made of stainless steel and have a mesh size of $50 \mu \mathrm{m}$ and a wire diameter of $35 \mu \mathrm{m}$. The screens are enclosed by a mesh and an O-ring with an inner diameter of $40 \mathrm{~mm}$ to fix the screens inside the screen holder. 


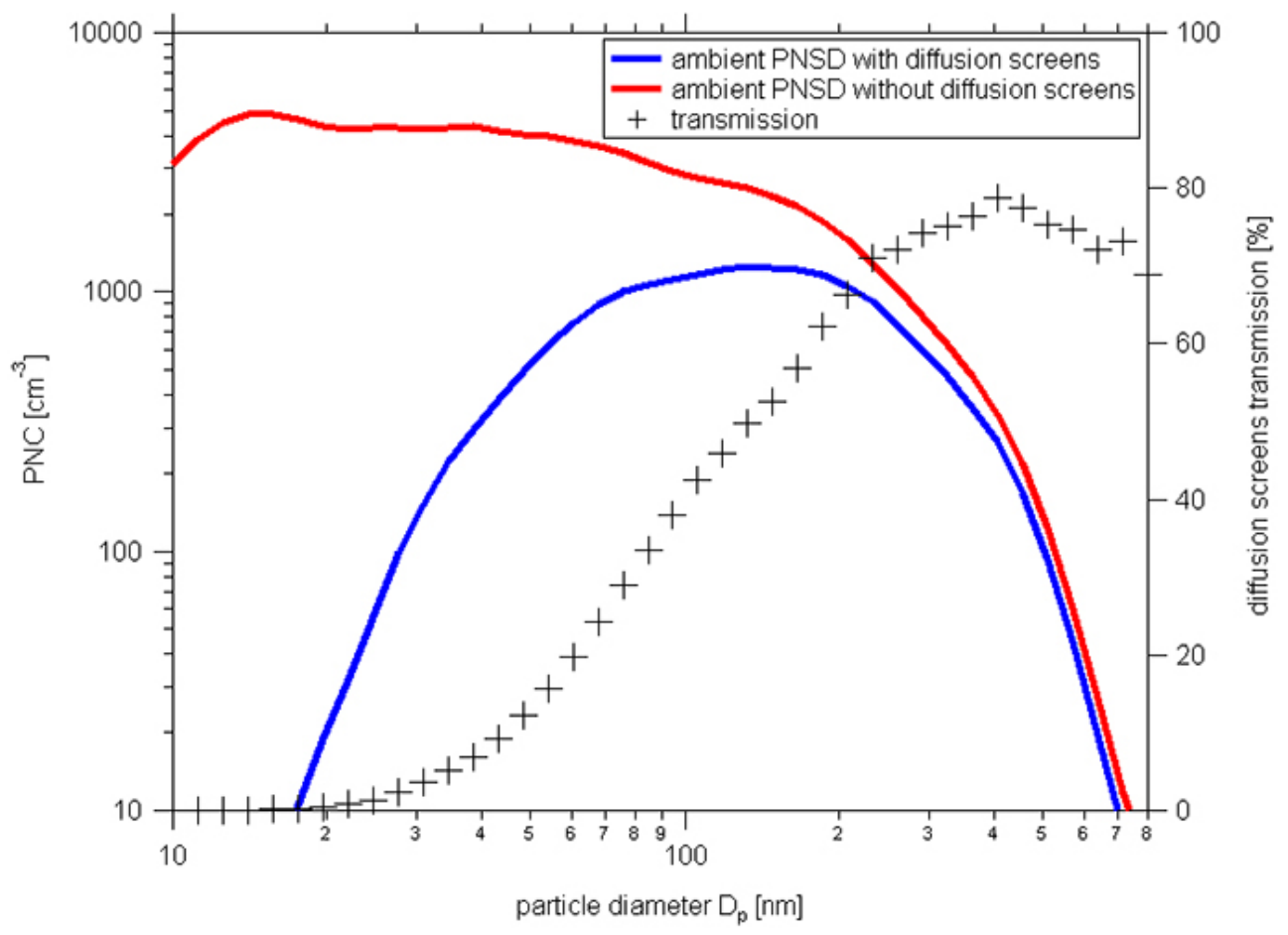

Fig. 5. Exploring the collection efficiency of the diffusion screens: comparison of synchronous measurements of a PNSD with (blue solid line) and without (red solid line) diffusion screens. Black crosses represent the transmission of the diffusion screens.
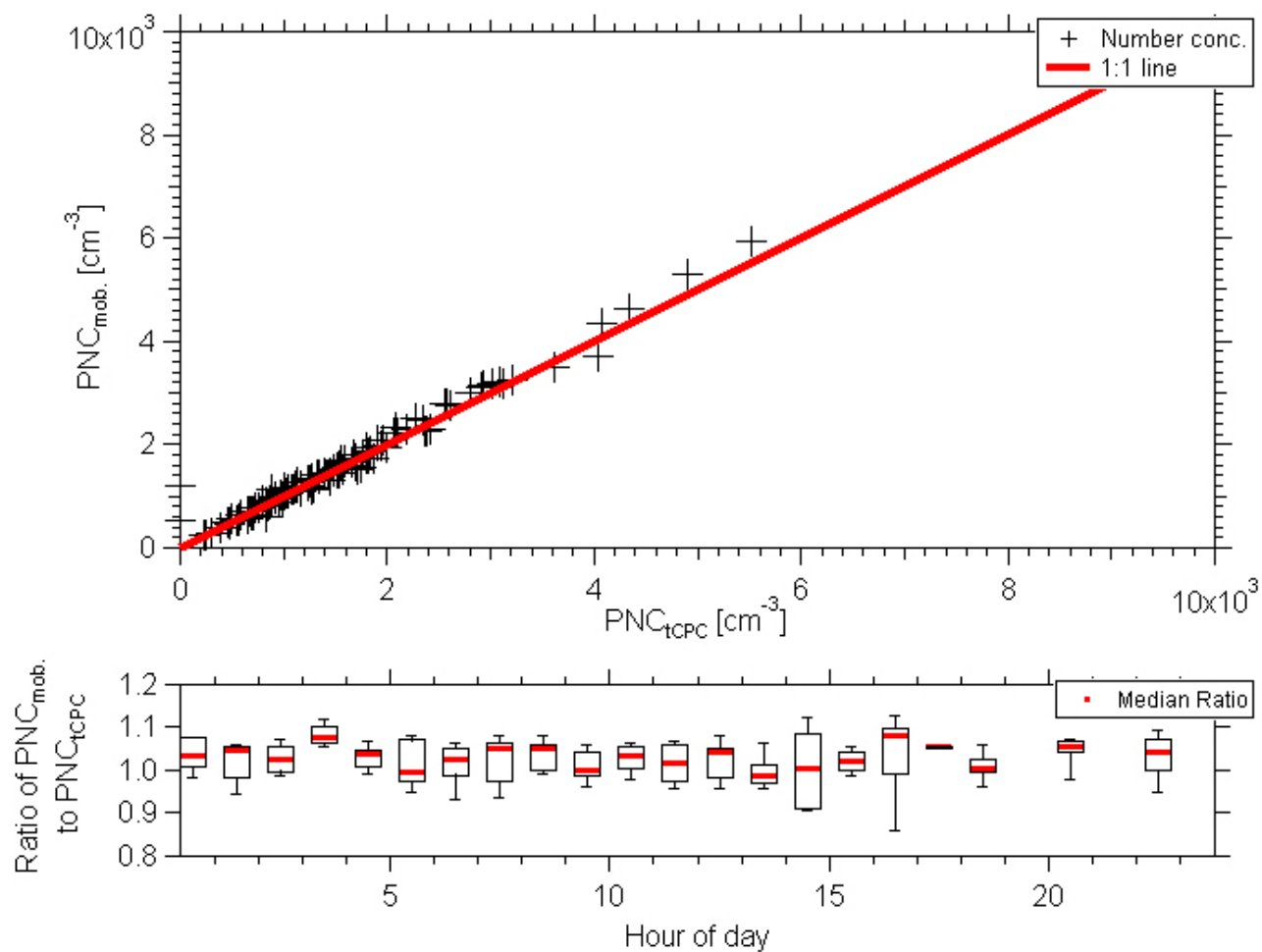

Fig. 6. Same as Fig. 3 but with diffusion screens. 

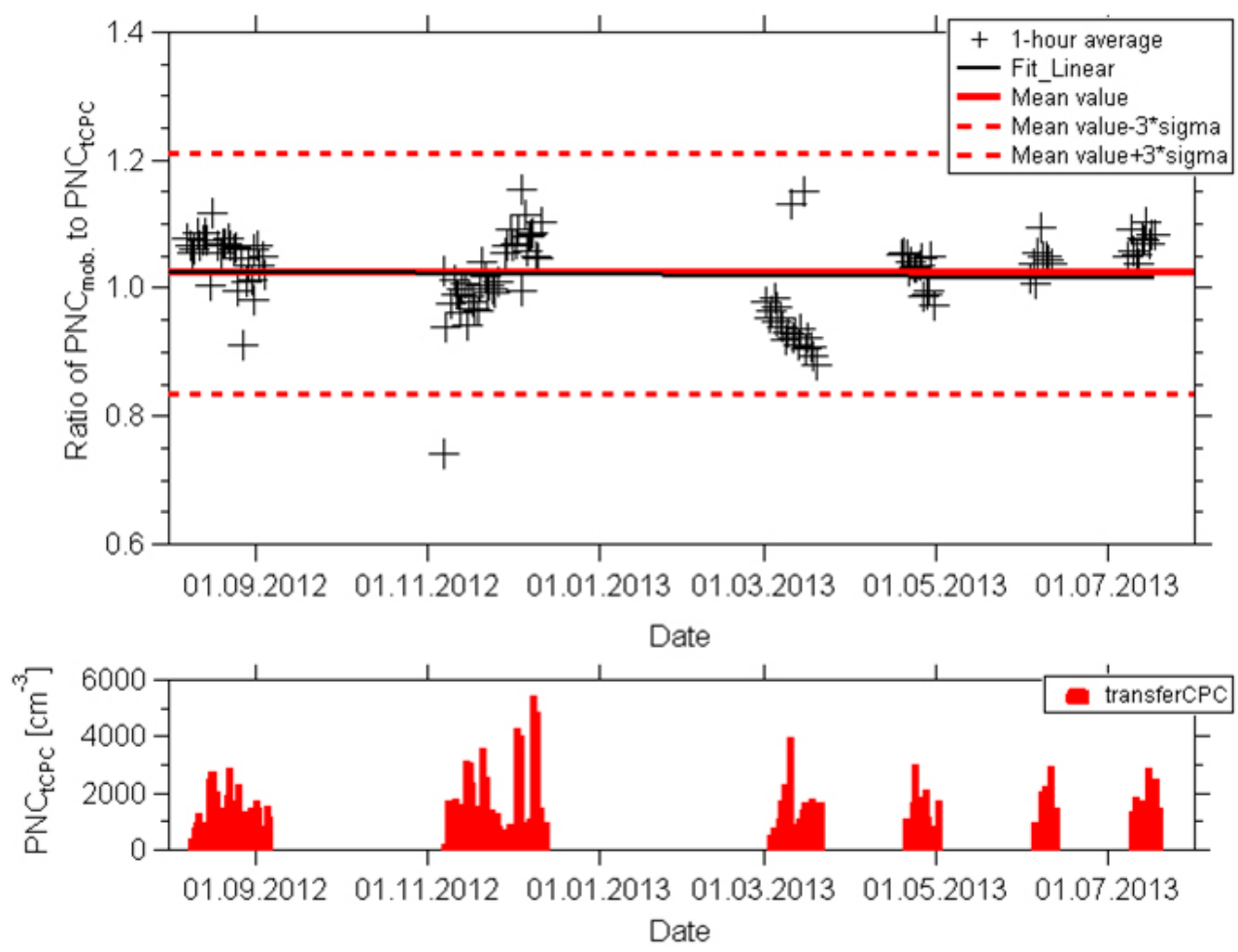

Fig. 7. Results from the diffusion screen measurements for the Annaberg-Buchholz site from 1 August 2012 to 1 August 2013. Upper graph: quality control chart shows entire mean value (red solid line), 99th confidence interval (red dashed line), and linear fit (black solid line) adapted from $1 \mathrm{~h}$ averages (black crosses). Lower graph: time series of the PNC from the transfer CPC.

Figure 5 illustrates the two PNSDs with and without diffusion screens. It is worth mentioning that both size distributions are measured at the same time. Black crosses in Fig. 5 represent the entire transmission of the diffusion screens, determined as the ratio of both PNSDs. Particles smaller than $D_{\mathrm{p}}=20 \mathrm{~nm}$ are completely removed by the diffusion screens. Thus, comparisons such as $\mathrm{PNC}_{\mathrm{mob}}$. vs. $\mathrm{PNC}_{\mathrm{tCPC}}$ are less prone to fluctuations in the ambient aerosol in that size range. For particles larger than $D_{\mathrm{p}}=20 \mathrm{~nm}$, the transmission of the diffusion screens increases and culminates at about $80 \%$ for the largest particles.

\section{Data processing}

The following section describes the data processing of the zero-air and diffusion screen measurements starting from the raw data. The raw data set comprises the electrical particle mobility distribution covering a mobility diameter range from 10 to $800 \mathrm{~nm}$, as well as diagnostic parameters (i.e. temperature, relative humidity, and flow rates of the aerosol and sheath air). Information about status parameters ( 0 and 1$)$ for zero-air measurements, diffusion screen measurements, and service maintenance are also provided.

The processing of the electrical mobility distribution into the true PNSD contains multiple charge correction (Pfeifer et al., 2014), coincidence correction of the CPC, and correction for diffusional losses in the mobility particle size spectrometer (Wiedensohler et al., 2012). The correction of the counting efficiency of the CPC was not applied for comparisons of CPCs from the same type (here: CPC from the mobility particle size spectrometer and transfer CPC). Diagnostic parameters were used for automatic flagging of data outside the confidence range. Finally, the respective data were removed from the entire data set during data processing. The range for valid data are: $10-30{ }^{\circ} \mathrm{C}$ for temperature, $0-40 \%$ for relative humidity, $\pm 2 \%$ of the set point value for the sheath air flow rate, and $\pm 5 \%$ of the set point value for the aerosol flow rate according to the recommendations (Wiedensohler et al., 2012). With regard to the status parameters, the entire data set was classified automatically into data sets for regular measurements without service maintenance, zero-air measurements, as well as diffusion screen measurements. The first and the last $5 \mathrm{~min}$ of each zero-air measurement, typically referred as blanking time, were disregarded. The PNSD measured with diffusion screens were integrated over the entire size range yielding $\mathrm{PNC}_{\mathrm{mob}}$. Finally, these new data sets were averaged (arithmetic mean) to a lower time resolution of about $1 \mathrm{~h}$. 
Table 1. Results of the zero-air measurements from 1 August 2012 to 1 August 2013 for the Annaberg-Buchholz site.

\begin{tabular}{|c|c|c|c|}
\hline & Minimum PNC $\left[\mathrm{cm}^{-3}\right]$ & $\begin{array}{l}\text { Annaberg-Buchholz } \\
\text { Mean PNC }\left[\mathrm{cm}^{-3}\right]\end{array}$ & Maximum PNC $\left[\mathrm{cm}^{-3}\right]$ \\
\hline $10-20 \mathrm{~nm}$ & 0 & 0.1 & 2.0 \\
\hline $20-30 \mathrm{~nm}$ & 0 & 0 & 1.0 \\
\hline $30-50 \mathrm{~nm}$ & 0 & 0.1 & 1.8 \\
\hline $50-70 \mathrm{~nm}$ & 0 & 0 & 1.4 \\
\hline 70-100 nm & 0 & 0 & 0.7 \\
\hline $100-200 \mathrm{~nm}$ & 0 & 0.1 & 1.0 \\
\hline $200-800 \mathrm{~nm}$ & 0 & 0 & 0.2 \\
\hline
\end{tabular}

\section{Results and discussion}

The following section depicts exemplary results of the automated function control for the Annaberg-Buchholz site after necessary software and hardware upgrades of the mobility particle size spectrometer were completed.

Figure 6 illustrates the same as Fig. 3 but with diffusion screens. In contrast to Fig. 3, the $1: 1$ line goes through the scatter plot and the ratio is about unity and does not show any diurnal variation. In turn, parameters with a distinct diurnal curve, i.e. temperature, relative humidity, and global radiation (induce new particle formation) do not have an influence on the results.

Figure 7 presents the results of diffusion screen measurements in another way, which will be useful to judge the instrument performance. As before, the same 1-year period is used. The upper graph presents the ratio of $\mathrm{CPC}_{\text {mob. }}$. to $\mathrm{CPC}_{\mathrm{tCPC}}$ for each single diffusion screen measurement (black crosses) and the mean value of the entire period (red solid line). The mean value is 1.02 (offset of $2 \%$ ) and there is no significant trend visible.

Nevertheless, variability can be seen from cycle to cycle, which cannot be fully explained at present. One hypothesis would be primary solid particles in the accumulation size range from traffic emissions of a street passing the site in a distance of about $10 \mathrm{~m}$. An influence of $\mathrm{PNC}_{\mathrm{tCPC}}$, which is illustrated on the lower graph, can be excluded. Obviously, $\mathrm{PNC}_{\mathrm{tCPC}}$ does not correlate with the ratio. Besides the cycle to cycle variability, there is a certain intra-cyclic variability as well, which is caused by the automatic function control set up itself. In particular, the transfer CPC evaluates all size classes simultaneously, whereas the mobility particle size spectrometer measures the size classes successively. Fast variations in PNC or fast variations in the shape of the PNSD cannot be detected by the automated function control. A special case of intra-cyclic variability occurred during November 2012 and March 2013. Here, the focusing inner nozzle of the CPC as part of the mobility particle size spectrometer was increasingly clogged accompanied with a decrease of the particle counting efficiency.

An aim of this work is to derive tolerance criteria based on the diffusion screen and zero-air measurements of the pre- vious year. These tolerance criteria will help to judge the instrument performance in future and can be stringently applied to judge data valid or invalid. The conduction of tolerance criteria for the diffusion screens using error propagation would lead to unrealistic errors and is therefore impracticable. Instead, we employed a statistical approach, which is also used for equivalence checks of reference instruments in air quality monitoring networks. There, the mean value \pm three standard deviations $(\sigma)$ is applied to rate the performance of a measurement device. For our exemplary data set, the mean $\pm 3 \sigma$ value is $1.02 \pm 0.19$ (cf. upper graph in Fig. 7). Thus, the tolerance criteria for the mobility particle size spectrometer at the Annaberg-Buchholz site would be 0.83 and 1.21 , respectively. Presumably, these tolerance criteria are site specific.

In practice, these tolerance criteria could be applied as follows: if the mean value of the diffusion screen measurements of one cycle (duration typically 2 weeks) drops below or exceeds the tolerance criteria, further inspections should follow in order to fix the problem. As a consequence, the regular ambient aerosol measurements would be invalidated as long as the subsequent diffusion screen measurement turns into the valid range.

Table 1 presents condensed results from the zero-air measurements for seven size ranges $(10-20 \mathrm{~nm}, 20-30 \mathrm{~nm}$, $30-50 \mathrm{~nm}, 50-70 \mathrm{~nm}, 70-100 \mathrm{~nm}, 100-200 \mathrm{~nm}$, and 200 $800 \mathrm{~nm}$ ) including minimum, maximum, and entire mean values. The highest PNC of $2 \mathrm{~cm}^{-3}$ was recorded for the smallest size class from $10-20 \mathrm{~nm}$. The establishment of a tolerance criterion for the zero air is based on the lower detection limit for the PNC and the permeation rate of the zero filter. The lower detection limit is dependent on the false count rate of the CPC, which is in turn so low that the resultant lower detection limit is approximately zero. The permeation rate of the used HEPA filter is approximately $5 \times 10^{-3}$ for $300 \mathrm{~nm}$ sized particles. With regard to common particle concentrations measured at ambient conditions, we suggest a tolerance criterion for the PNC of each size range that is $2 \mathrm{~cm}^{-3}$. 


\section{Summary and conclusion}

This paper presents a new concept in the quality control for long-term measurements with mobility particle size spectrometers. Quality assured measurements are, for example, a precondition for sensitive intercomparisons of measurement data recorded at different observation sites. The automated function control fulfils the requirements of measurement networks for monitoring the system performance quasicontinuously. The automated function control comprises diffusion screen and zero-air measurements and checks the instrument performance with respect to the particle number concentration. The special feature of the automated function control is its ability to get a faster response on the system stability than recommended on-site comparisons with a reference instrument from the calibration facility. A major advantage of the automated function control is the softwaredriven switching between regular ambient air, zero air, and diffusion screen measurement. Moreover, the maintenance work is quite low. Beside the setting up and dismounting of the transfer CPC, the diffusion screens should be regularly cleaned in an ultrasonic bath and the filter cartridge has to be replaced from time to time. The mobility particle size spectrometer has to be upgraded by one further CPC and some hardware parts and the software must be updated.

The performance of a mobility particle size spectrometer equipped with an automated function control is exemplarily shown for the measurement site Annaberg-Buchholz for the 1-year period 1 August 2012 to 1 August 2013. For the particle number concentration, an offset of $2 \%$, but no significant trend, was found from the comparison with the transfer CPC for the 1-year period. Statistical derived tolerance criteria were calculated to 0.83 and 1.21 for the same period. For the zero-air measurement, a tolerance criterion for the particle number concentration of $2 \mathrm{~cm}^{-3}$ is suggested.

Acknowledgements. The concept and the technical realization of this study were funded within the service contract Az.510345.40/32/3 by the LfULG in the frame of the UFP 2011 project (German title: Entwicklung und Erprobung einer automatischen Funktionskontrolle für die Messung ultrafeiner Partikel in der Außenluft mit Mobilitätsspektrometern).

This study was generously supported by the EU-Ziel3 project UltraSchwarz (German title: Ultrafeinstaub und Gesundheit im Erzgebirgskreis und Region Usti) under grant number 100083657 and the INTERREG IVb project UFIREG (title: Ultrafine Particles - an evidence based contribution to the development of regional and European environmental and health policy) under grant number 3CE288P3. UFIREG is implemented through the CENTRAL EUROPE Programme co-financed by the ERDF. Figure 1 was kindly prepared by A. Haudek (TROPOS). We also thank A. Knaus and H.-G. Kath (both from Saxon State Department for Agricultural and Environmental Operations) for the data evaluation and technical support of the measurements carried out in Annaberg-Buchholz.

Edited by: P. Herckes
References

Asmi, A., Wiedensohler, A., Laj, P., Fjaeraa, A. M., Sellegri, K., Birmili, W., Weingartner, E., Baltensperger, U., Zdimal, V., Zikova, N., Putaud, J. P., Marinoni, A., Tunved, P., Hansson, H. C., Fiebig, M., Kivekäs, N., Lihavainen, H., Asmi, E., Ulevicius, V., Aalto, P. P., Swietlicki, E., Kristensson, A., Mihalopoulos, N., Kalivitis, N., Kalapov, I., Kiss, G., de Leeuw, G., Henzing, B., Harrison, R. M., Beddows, D., O’Dowd, C., Jennings, S. G., Flentje, H., Weinhold, K., Meinhardt, F., Ries, L., and Kulmala, M.: Number size distributions and seasonality of submicron particles in Europe 2008-2009, Atmos. Chem. Phys., 11, 5505-5538, doi:10.5194/acp-11-5505-2011, 2011.

Bates, T. S., Huebert, B. J., Gras, J. L., Griffiths, F. B., and Durkee, P. A.: International global atmospheric chemistry (IGAC) project's first aerosol characterization experiment (ACE 1): Overview, J. Geophys. Res., 103, 16297-16318, doi:10.1029/97JD03741, 1998.

Birmili, W., Weinhold, K., Nordmann, S., Wiedensohler, A., Spindler, G., Müller, K., Herrmann, H., Gnauk, T., Pitz, M., Cyrys, J., Flentje, H., Nickel, C., Kuhlbusch, T. A. J., Löschau, G., Haase, D., Meinhardt, F., Schwerin, A., Ries, L., and Wirtz, K.: Atmospheric aerosol measurements in the German Ultrafine Aerosol Network (GUAN)-Part 1: Soot and particle number size distributions, Gefahrst. Reinh. Luft, 69, 137-145, 2009.

Heintzenberg, J.: The SAMUM-1 experiment over Southern Morocco: overview and introduction, Tellus, 61B, 2-11, doi:10.1111/j.1600-0889.2008.00403.x, 2009.

Huebert, B. J., Bates, T., Russell, P. B., Shi, G., Kim, Y. J., Kawamura, K., Carmichael, G., and Nakajima, T.: An overview of ACE-Asia: Strategies for quantifying the relationships between Asian aerosols and their climatic impacts, J. Geophys. Res., 108, 8633, doi:10.1029/2003JD003550, 2003.

Löschau, G., Wiedensohler, A., Birmili, W., Rasch, F., Spindler, G., Müller, K., Wolf, U., Hausmann, A., and Herrmann, H. Umweltzone Leipzig; Teil 1: Ausgangsbeurteilung, Sächsisches Landesamt für Umwelt, Landwirtschaft und Geologie, Dresden, 83 pp., 2012.

Löschau, G., Wiedensohler, A., Birmili, W., Rasch, F., Spindler, G., Müller, K., Wolf, U., Hausmann, A., Böttger, M., Anhalt, M., and Herrmann, H.: Umweltzone Leipzig; Teil 2: Immissionssituation 2011, Sächsisches Landesamt für Umwelt, Landwirtschaft und Geologie, Dresden, 89 pp., 2013.

Paasonen, P., Asmi, A., Petäjä, T., Kajos, M. K., Aijala, M., Junninen, H., Holst, T., Abbatt, J. P. D., Arneth, A., Birmili, W., van der Gon, H. G., Hamed, A., Hoffer, A., Laakso, L., Laaksonen, A., Leatich, W. R., Plass-Dülmer, C., Pryor, S. C., Raisanen, P., Swietlicki, E., Wiedensohler, A., Worsnop, D. R., Kerminen, V. M., and Kulmala, M.: Warming-induced increase in aerosol number concentration likely to moderate climate change, Nature Geosci., 6, 438-442, doi:10.1038/ngeo1800, 2013.

Pfeifer, S., Birmili, W., Schladitz, A., Müller, T., Nowak, A., and Wiedensohler, A.: A fast and easy-to-implement inversion algorithm for mobility particle size spectrometers considering particle number size distribution information outside of the detection range, Atmos. Meas. Tech., 7, 95-105, doi:10.5194/amt-795-2014, 2014.

Raes, F., Bates, T., McGovern, F., and Van Liedekerke, M.: The 2nd Aerosol Characterization Experiment (ACE-2): general overview 
and main results, Tellus, 52B, 111-125, doi:10.1034/j.16000889.2000.00124.x, 2000.

Romakkaniemi, S., Arola, A., Kokkola, H., Birmili, W., Tuch, T., Kerminen, V. M., Räisänen, P., Smith, J. N., Korhonen, H., and Laaksonen, A.: Effect of aerosol size distribution changes on $\mathrm{AOD}, \mathrm{CCN}$ and cloud droplet concentration: Case studies from Erfurt and Melpitz, Germany, J. Geophys. Res, 117, D07202, doi:10.1029/2011JD017091, 2012.

Russell, A. G. and Brunekreef, B.: A Focus on Particulate Matter and Health, Environ. Sci. Technol., 43, 4620-4625, doi:10.1021/es9005459, 2009.

UBA: http://www.env-it.de/stationen/public/open.do, last access: 24 July 2013, 2013.

Wichmann, H.-E., Spix, C., Tuch, T., Wölke, G., Peters, A., Heinrich, J., Kreyling, W. G., and Heyder, J.: Daily mortality and fine and ultrafine particles in Erfurt, Germany. Part I, Role of particle number and particle mass, Health Effects Institute, Cambridge, Research Report 98, 96 pp., 2000.
Wiedensohler, A., Birmili, W., Nowak, A., Sonntag, A., Weinhold, K., Merkel, M., Wehner, B., Tuch, T., Pfeifer, S., Fiebig, M., Fjäraa, A. M., Asmi, E., Sellegri, K., Depuy, R., Venzac, H., Villani, P., Laj, P., Aalto, P., Ogren, J. A., Swietlicki, E., Roldin, P., Williams, P., Quincey, P., Hüglin, C., Fierz-Schmidhauser, R., Gysel, M., Weingartner, E., Riccobono, F., Santos, S., Grüning, C., Faloon, K., Beddows, D., Harrison, R. M., Monahan, C., Jennings, S. G., O’Dowd, C. D., Marinoni, A., Horn, H. G., Keck, L., Jiang, J., Scheckman, J., McMurry, P. H., Deng, Z., Zhao, C. S., Moerman, M., Henzing, B., de Leeuw, G., Löschau, G., and Bastian, S.: Particle mobility size spectrometers: harmonization of technical standards and data structure to facilitate high quality long-term observations of atmospheric particle number size distributions, Atmos. Meas. Tech., 5, 657-685, doi:10.5194/amt5-657-2012, 2012. 